\title{
Comparativo entre instrumentos pluviométricos experimentais e automáticos
}

\author{
Marcos Alexandre Milanesi ${ }^{(a)}$, Rogério Rozolen Alves ${ }^{(b)}$ e Emerson Galvani ${ }^{(c)}$
}

(a) Departamento de Geografia/FFLCH/Universidade de São Paulo, ma.milanesi@usp.br

(b) Departamento de Geografia/FFLCH/Universidade de São Paulo, rroz@usp.br

(c) Departamento de Geografia/FFLCH/Universidade de São Paulo, egalvani@usp.br

\section{Eixo: Climatologia em diferentes níveis escalares: mudanças e variabilidades}

\begin{abstract}
Resumo
O objetivo deste estudo foi a comparação entre os totais de chuva coletados por diferentes instrumentos pluviométricos com a finalidade de encontrar seus desvios e correlações, a similaridade entre eles, e estabelecer, se possível, um valor correcional entre um modelo experimental em relação a um modelo automático.Os dados foram obtidos por meio da compilação das informações pluviométricas da Estação Meteorológica Automática (EMA) do Laboratório de Climatologia e Biogeografia (LCB) do Departamento de Geografia (DG/USP) além das coletas por pluviômetros automático e de outros dois equipamentos manuais, os pluviômetros experimentais de Milanesi e Galvani (2012) no período de 02/dez/2015 a 28/nov/2016.A partir de observações dos diversos valores coletados procedeu-se à análise comparativa por meio do desvio padrão (S), das amplitudes absolutas (AMP) e do índice de variação (IVar) e posterior identificação dos coeficientes de determinação e coeficiente de correlação quando foi aplicado o teste a distribuição "t-Student". Os resultados conduziram à baixa homogeneidade das comparações quando considerados os totais mais baixos (maior variação no inverno), subvaloração dos totais quando observadas as intensidade das chuvas e o equipamento automatico (maior intensidade leva a maiores erros), coeficiente de determinação relativamente elevado, onde na média, o poder explicativo do modelo foi de $98 \%$ considerando os totais e as respectivas superfícies coletoras. Já quando considerado o coeficiente de correlação $(0,99)$, este foi significativo ao nível de $95 \%$ de probablidade para o teste "t-Student".
\end{abstract}

Palavras chave: Clima, pluviômetro, chuva, comparação.

\section{Introdução}

O uso de sensores eletrônicos nos estudos dos atributos do clima e do tempo tem sido cada vez mais popularizados dada a redução de seu tamanho, o aumento da resolução temporal e melhorias em sua precisão - características possibilitadas por conta dos avanços técnico-científicos que permitiram o desenvolvimento de novos equipamentos para o monitoramento, coleta, transmissão e armazenamento de dados multivariados em tempo real. Por outro lado temos a possibilidade de construir, a partir de materiais simples e mais baratos, alguns dos instrumentos por nós utilizados em nosso dia-dia e em nossas pesquisas; equipamentos manuais, normalmente experimentais, que por força do cálculo, deveriam apresentar homogeneidade em relação aos mesmos dados observados quando considerados os equipamentos automáticos. A possibilidade de verificar-se a homogeneidade entre os equipamentos 


\section{OS DESAFIOS DA GEOGRAFIA FÍSICA NA FRONTEIRA DO CONHECIMENTO \\ Instituto de Geociências - Unicamp \\ Campinas - SP \\ 28 de Junho à 02 de Julho de 2017}

automáticos e os de coleta manual podem gerar informações indicando se há a necessidade de alguma correção.

Em estudos do clima, ou de seus elementos em separado, os sensores eletrônicos possibilitam a aquisição de dados praticamente em tempo real, o que acelera os processos decisórios relacionados aos manejos hídrico, florestal, às classificações climáticas, aos zoneamentos agroecológicos e aos planos diretores municipais.

Pluviômetros são equipamentos que medem a quantidade de chuva precipitada em determinado ponto do espaço terrestre. Normalmente são compostos de um reservatório (de volume suficiente para coletar precipitações de diferentes alturas) e uma superfície/área coletora (Ac) que é a "boca" do pluviômetro e, que possibilitam a totalização dos valores em intervalos temporais diferenciados. A boca do equipamento pode ser aberta: adequada a totais de $24 \mathrm{~h}$, entretanto, sujeitas à evaporação - como no pluviômetro padrão Ville de Paris ( $\mathrm{Ac}=400 \mathrm{~cm}^{2}$ e um total nominal de $125 \mathrm{~mm}$ ); ou não, quando acoplada à boca pode ser instalado um funil que apresenta um orifício concentrador no fundo que minimize os processos evaporatórios, permitindo a coleta da chuva em intervalos maiores. A superfície coletora não é normalizada (a não ser no equipamento padrão) e, o cálculo da lâmina precipitada é feito com base no volume de água coletado no pluviômetro, a partir da equação 1, em que:

$$
\mathbf{V}=\mathbf{A}^{*} \mathbf{h}
$$

V - altura da chuva recolhida pluviômetro (mm);

A - área da superfície coletora do pluviômetro, e; $\left(\mathrm{cm}^{2}\right)$

$\mathrm{h}$ - altura do reservatório. $(\mathrm{cm})$

Podem ser, com abordado anteriormente, manuais ou automático: os primeiros dependem de um observador que faça a coleta, a totalização e a sistematização do precipitado, enquanto os outros necessitam de um observador para a transfêrencia dos dados e ou manutenção do equipamento, pois que registram a informação eletrônica em hard drives ou flash memories de capacidade limitada, podendo funcionar por períodos indeterminados dependendo das configurações determinadas e da potência da bateria utilizada, e, evidentemente, da frequência da precipitação local.

Sentelhas et al. (1997), demonstraram a baixa variabilidade entre os valores médios dos principais elementos meteorológicos em estudos comparativos entre estações meteorológicas convencionais e automáticas.

Em Souza, Galvani, Assunção (2003) temos a questão da representatividade dos dados quando da substituição/implantação de uma estação meteorológica convencional (EMC) por uma EMA 
OS DESAFIOS DA GEOGRAFIA FÍSICA NA FRONTEIRA DO CONHECIMENTO

Instituto de Geociências - Unicamp

Campinas - SP

28 de Junho à 02 de Julho de 2017

(automática), quando foi questionado se os diferentes tipos de equipamentos responderiam com valores semelhantes ou de igual precisão. Os resultados obtidos apresentaram significativa concordância entre os dados observados na EMC e na EMA, estando a variação dos valores dos atributos temperatura e umidade relativa média, dentro da faixa de precisão dos sensores. Apesar dos baixos erros, os dados de pressão atmosférica apresentaram diferenças significativas devido à diferença altimétrica entre os sitios das duas estações.

Para Chevallier (1993) a disponibilidade de bons e confiáveis dados de chuva é difícil, embora a medição e os aparelhos sejam simples - a presença de falhas e erros grosseiros podem inconsistir os dados, sendo necessário bons conhecimentos do método de aquisição, do equipamento e do sítio de instalaçãodos lugares de instalação.

Sob quaisquer hipóteses é importante instalar o equipamento de modo que os valores totalizados sejam considerados condizentes com a precipitação da área, quando e onde são mitigadas as características físicas dos sítios de instalação capazes de influenciar a coleta e a geração de erros (a normatização oficial para homegeneizar a coleta dos dados é preconizada pela OMM) e propõe, ao menos, o estabelecimento de uma altura média entre 1 e 1,5 m acima do solo para a superficie coletora (altura da boca do pluviômetro). Admite-se que a proximidade do equipamento a uma distância equivalente a duas vezes a altura de algum obstáculo melhore a eficácia da coleta, mas ao mesmo tempo, se instalado em ambiente totalmente aberto sofre também a influência de correntes aerológicas mais intensas, influindo na precisão da coleta.

Diversas são as fontes de erros relacionadas às medidas pluviométricas desde as obstruções físicas, perdas evaporatórias, aderencia à parede das provetas medidoras, respingos para dentro ou para fora do recipinte coletor, paralaxe, entre outros. Mas indiferentemente dos erros grosseiros, o pesquisador dever ter em mente que cada tipo de chuva, ou cada episódio, pode apresentar diferenças significativas devido a suas características intrínsecas de quantidade, duração e intensidade (WMO, 1996).

Braga e Fernandes (2007) discutem a performance de pluviômetros do tipo "Tipping Bucket" (báscula). Abordam os padrões construtivos dos equipamentos, e constatam em ensaios de laboratório, sub-medições, especialmente durante eventos extremos. Seus resultados observam a partir de quatro modelos diferentes de pluviômetros de báscula, a existência de motivos para preocupação quanto à utilização deste tipo de aparelho.

Braga et al. (2007) realizam testes em laboratório visando apurar as diferenças entre pluviômetros automáticos de básculas que tem sido largamente utilizado em estações automáticas de coleta de dados climatológicos no Brasil e a ocorrência de erros em suas medições. A investigação do funcionamento dos equipamentos utilizados na Bacia experimental do Rio Barigüi revelou erros substanciais de medida. Os resultados indicam consideráveis fontes de incerteza nas medições produzidas pelos 
pluviômetros de báscula ja que a análise indicou haver necessidade de ampliar o estudo, para que a performance real deste tipo de equipamento seja melhor compreendida.

Braga et. al. (2008) desenvolvem experimentos para apurar as diferenças em medições entre 7 pluviômetros de báscula, considerados como de alta performance, os quais foram avaliados em sua capacidade de responder adequadamente à ocorrência de chuvas intensas, no Laboratório de Monitoramento Eletrônico do Departamento de Hidráulica e Saneamento da Universidade Federal do Paraná. Apresentam uma reflexão sobre o funcionamento de pluviômetros com base em experimentos laboratoriais utilizando de bombas peristálticas de precisão para a simulação de eventos pluviométricos. Os resultados laboratoriais confirmaram tendência à sub-medição, especialmente, durante eventos de chuva intensa.

Souza et. al. (2013) avaliaram entre 2008 e 2009 as características funcionais e os valores de precipitação medidos com oito modelos de pluviômetros alternativos em relação aos valores medidos com um pluviômetro tipo Ville de Paris (padrão). As medidas de precipitação diária foram analisadas considerando coeficientes de correlação linear $(\mathrm{R})$, desvio por intervalo de classe de precipitação e índices de concordância e confiança. Verificaram que o pluviômetro constituído de uma garrafa PET (politereftalato de etileno) de água mineral de 1,5 L contendo um funil interno feito a partir de outra garrafa de mesma marca e volume mostrou-se mais adequado para realizar medidas de precipitação na falta do pluviômetro Ville de Paris.

Desta forma o objetivo central deste estudo foi avaliar as diferenças encontradas comparativamente entre dados totais de chuva coletados por pluviômetros automáticos e manuais (experimentais), numa mesma localidade e propor um fator corretivo entre eles.

\section{Material e método}

O experimento foi realizado na área da Estação Meteorológica Automática (EMA) do Laboratório de Climatologia e Biogeografia (LCB) do Departamento de Geografia da USP - localizado sob as coordenadas geográficas: latitude $23^{\circ} 33^{\prime} \mathrm{S}$, longitude $46^{\circ} 43^{\prime} \mathrm{W}$, altitude $739 \mathrm{~m}$, dentro da Cidade Universitária Armando Salles de Oliveira, em São Paulo. (Figura 01). 


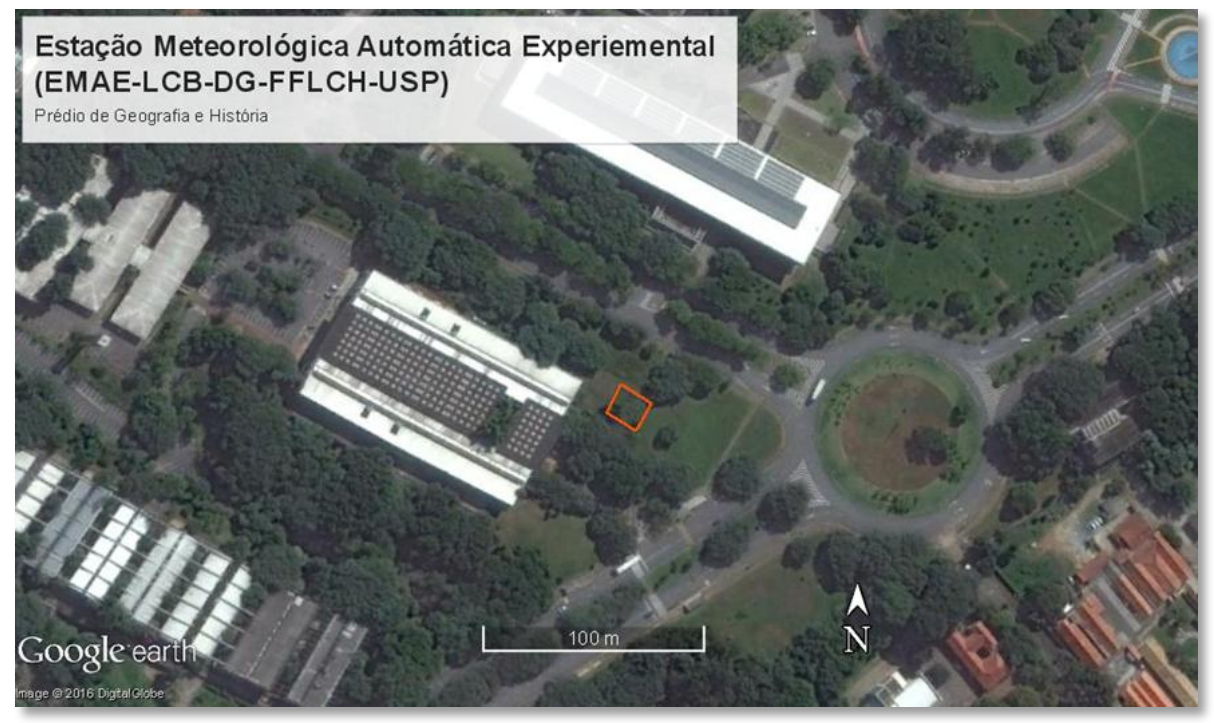

Figura 1. Localização da EMA junto ao Prédio de Geografia e História no campus da USP. Fonte: Google Earth (2017). Org.: Milanesi (2015)

É uma área gramada de $50 \mathrm{~m}^{2}$, aproximadamente, que abriga além de uma torre com outros sensores, os experimentos dos alunos e uma árvore a SW. Sua frente (SE) é um declive gramado inferior a $15^{\circ}$, desobstruído horizontalmente de árvores numa visada de $90^{\circ}$ neste sentido (Figura 02).

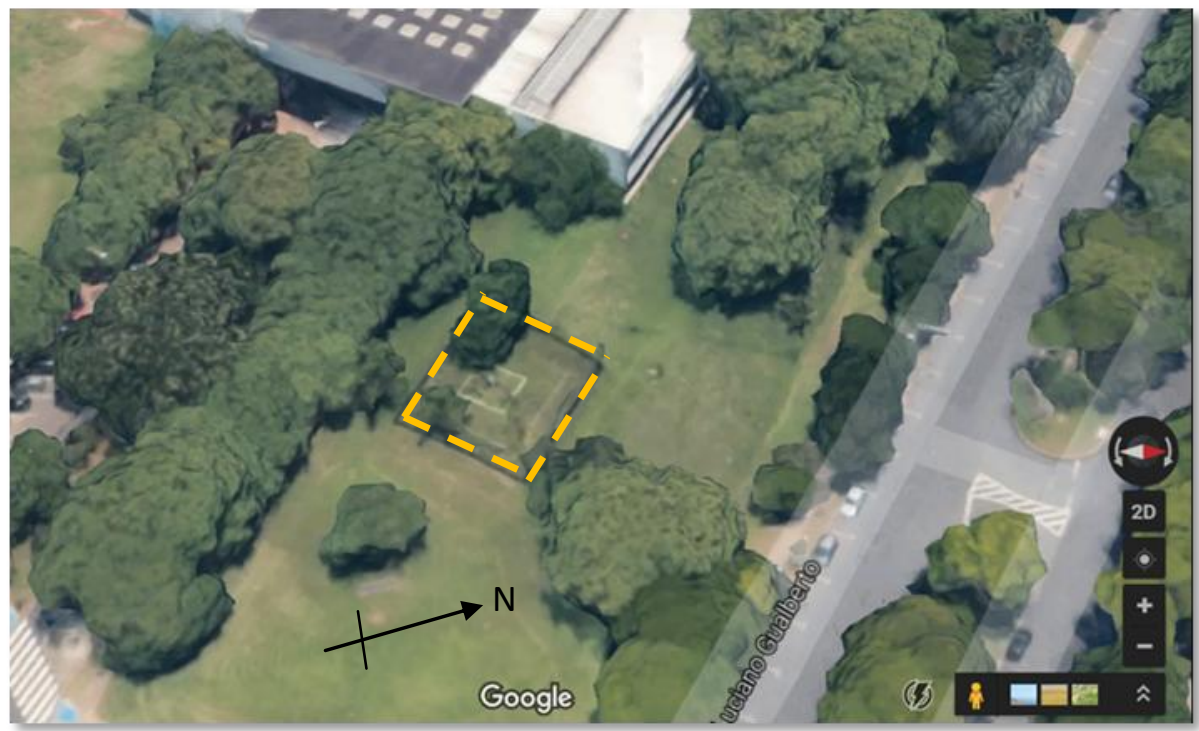

Figura 2. Figura ilustrativa da área da EMA. Fonte: Google Maps (2017). Org.: Milanesi (2015)

O período de coleta dos dados compreendeu 10 meses de observações referentes ao período de 02 de dezembro de 2015 a 28 de setembro de 2016, totalizando 302 dias. Já os dados pluviométricos trabalhados neste estudo foram coletados a partir de 4 equipamentos: 2 pluviômetros automáticos 


\section{OS DESAFIOS DA GEOGRAFIA FÍSICA NA FRONTEIRA DO CONHECIMENTO \\ Instituto de Geociências - Unicamp \\ Campinas - SP \\ 28 de Junho à 02 de Julho de 2017}

(Texas Eletronics/EMA e Squitter Ambiental) - apenas o pluviômetro Squitter Ambiental, retificando, registrou dados a partir de 14 de março de 2016, num total de 7 coletas contra 13 dos outros equipamentos, e, 2 pluviômetros experimentais de Milanesi e Galvani (2012). Os pluviômetros foram instalados paralelamente ao pluviômetro da EMA, que numa linha reta esteve orientada de NW para SE com altura da área de captação estimada em 1,5m, conforme Figura 3.

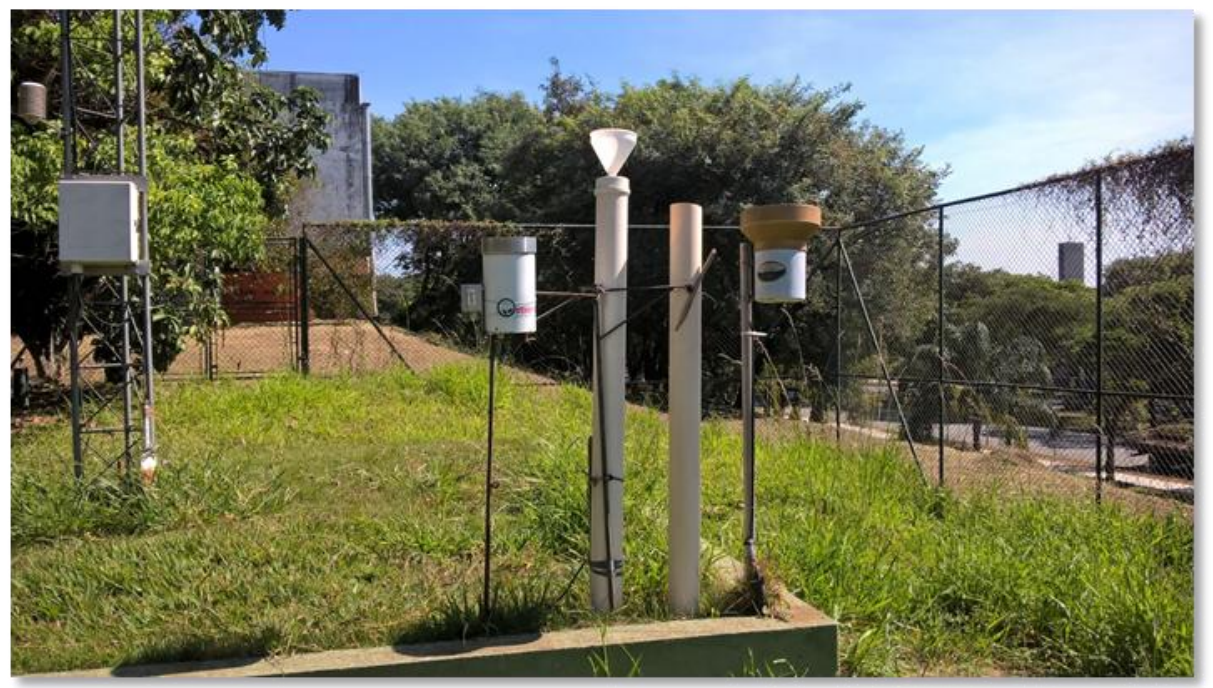

Figura 3. Pluviômetros utilizados neste estudo: Squitter Ambiental (esq.), 02 pluviômetros experimentais ao centro (com e sem) e Texas Instruments.

(Autor: Milanesi, 2015)

O modelo TE525M, Texas Eletronics (esq.), pertence à EMA do LCB (DG/FFLCH/ USP). É um pluviômetro automático de báscula, que registra dados com amostras de $0,1 \mathrm{~mm}$, agrupando-os no datalogger da estação a cada cinco minutos de intervalo. Apresenta erro nomimal de $1 \%$ até $50 \mathrm{~mm} / \mathrm{h}$.

O pluviógrafo de modelo S1610 (dir.), da Squitter Ambiental, também é automático e registra os dados em um datalogger que fica junto ao próprio corpo do instrumento. Este modelo coleta chuva em amostras de 0,25 mm e armazena esses eventos com marcação de tempo, permitindo a posterior reconstrução da curva de precipitação do período. Também são calculados outros parâmetros relacionados com a quantidade e acúmulo de precipitação, como intensidade instantânea de chuva, chuva acumulada no período, na hora e no dia, não sendo, neste trabalho, utilizados os resultados destes cálculos, apenas os totais registrados em cada período das coletas. O datalogger deste modelo é acondicionado em um pequeno gabinete de alumínio, e sua memória permite armazenar até 16.350 eventos de chuva que depois podem ser transferidos para um microcomputador PC ou outro dispositivo de coleta. Um evento de chuva é definido como uma mudança de posição da báscula interna do pluviômetro (pulso). Se a graduação do pluviômetro é de $0,25 \mathrm{~mm}, 16.350$ eventos representam 4087,50 $\mathrm{mm}$ de chuva acumulada. Apresenta erro mínimo de $1 \%$ a $25 \mathrm{~mm} / \mathrm{h}$. 


\section{OS DESAFIOS DA GEOGRAFIA FÍSICA NA FRONTEIRA DO CONHECIMENTO \\ Instituto de Geociências - Unicamp \\ Campinas - SP \\ 28 de Junho à 02 de Julho de 2017}

Os pluviômetros experimentais de Milanesi e Galvani (2012) foram desenvolvidos pra atuarem especificamente em áreas remotas ou de dificil acesso, dada sua característica totalizadora, e foram utilizados tanto no mestrado (2007) do autor como nos trabalhos de Lima (2009) e Baratto et al. (2015). Originalmente esses equipamentos foram construídos para serem utilizados com o acoplamento do funil, porém, vandalismo e furtos determinaram seu cálculo também para aquele desprovido de funil. Dada a altura do reservatório $(150 \mathrm{~cm})$, em teoria, deveriam acumular as mesma alturas de chuva, contudo, devido às áreas de captação diferentes: $165,1 \mathrm{~cm}^{2}$ (COM funil) e $81,1 \mathrm{~cm}^{2}$ (SEM funil), o pluviômetro 'com funil' deveria totalizar matematicamente aproximadamente o dobro daquele total verificado no equipamento 'sem funil'. O limitante dos experimentais está na não possibilidade da qualificação da chuva, a gênese pluviométrica.

A Tabela 1 resume as características técnicas de cada equipamento, lembrando que não é possível calibrar o equipamento experimental, que necessita desta avaliação comparativa com o equipamento automático para sua aferição, de modo que tomamos o equipameto experimental 'com funil', de agora em diante COM, como nossa referência.

Tabela 1 - Ficha técnica dos pluviômetros utilizados na investigação.

\begin{tabular}{|c|c|c|c|c|}
\hline Pluviômetro & Diâmetro $(\mathbf{c m})$ & Área de captação $\left(\mathbf{c m}^{2}\right)$ & Resolução & Precisão \\
\hline SEM funil & 10 & 81,1 & totalizador & -- \\
\hline COM funil & 14 & 165,1 & totalizador & -- \\
\hline Squitter & 15,2 & 181,3 & $0,25 ~ \mathbf{~ m m}$ & $1,0 \%$ a $25 \mathrm{~mm} / \mathbf{h}$ \\
\hline Texas & 24,5 & 471,1 & $0,1 \mathrm{~mm}$ & $1,0 \%$ até $50 \mathrm{~mm} / \mathbf{h}$ \\
\hline
\end{tabular}

As comparações foram executadas a partir do cálculo da amplitude absoluta dos valores do equipamento COM e seus congêneres para estimativa das heterogeneidades da coleta. Posteriormente, foram calculadas medidas de tendência central (média) e dispersão: desvio padrão (que estima "a variação das amplitudes no entorno da média") e coeficiente de variação (a variação do desvio padrão em relação à média).

A relação analítica entre os valores coletados pelos diferentes equipamentos foi realizada por meio do cálculo comparativo entre os coeficiente de determinação $\left(\mathrm{R}^{2}\right)$ que é uma medida de ajuste a um modelo estatístico assim como a regressão linear simples, em relação aos valores observados, variando entre 1 e 0 - quando 1 valida percentualmente a possibilidade explicativa do modelo quanto aos valores observados. Já o coeficiente de correlação (R) foi utilizado para avaliar a relação natural existente entre os valores, podendo variar de $-1,0$ a 1,0: quando zero significa a inexistência da correlação. A distribuição "t-Student" é uma probabiblidade estatística que considera os valores mais extremos numa simulação da distribuição normal; aqui utilizaremos o nível de confiança de $95 \%$ de índice de probabilidade com 2 graus de liberdade. 


\section{OS DESAFIOS DA GEOGRAFIA FÍSICA NA FRONTEIRA DO CONHECIMENTO \\ Instituto de Geociências - Unicamp \\ Campinas - SP \\ 28 de Junho à 02 de Julho de 2017}

O índice de variação (Ivar) é representado pela razão entre os valores totais obtidos em equipamentos diferentes ou duas grandezas onde uma inclua a outra, variando de zero ao $\infty$ sendo menor a variação quando o quociente for aproximado de zero.

\section{Resultados e Discussão}

Os totais de chuva coletados por cada equipamento ao longo do tempo são apresentadas na Tabela 2. onde também se pode observar a temporalidade das coletas (dias), o desvio padrão (S), a amplitude absoluta (mm) e o índice de variação entre o pluviômetro Com x Squitter.

Tabela 2 - Alturas de chuva ( $\mathrm{mm}$ ) coletados no período do experimento em para cada equipamento.

\begin{tabular}{|c|c|c|c|c|c|c|c|c|c|c|c|c|c|}
\hline amostras & 1 & 2 & 3 & 4 & 5 & 6 & 7 & 8 & 9 & 10 & 11 & 12 & 13 \\
\hline intervalo temporal (dias) & 9 & 7 & 21 & 23 & 39 & 2 & 8 & 13 & 27 & 30 & 28 & 64 & 27 \\
\hline Totais (mm de chuva) & 2 a11/dez & $12 \mathrm{a} 18 / \mathrm{de}$ & $19 \mathrm{a} 08 / \mathrm{ja}$ & 09a31/ja & $1 / 2 \mathrm{a} 11 / \mathrm{n}$ & $12 / 03 \mathrm{a} 14$ & $115 / 03 / 20$ & $23 / 03(14$ & 05/04/11 & 102/05 (11 & $1 / 6$ a $29 /$ & $29 / 06(1 \mathrm{CC}$ & $01 / 09(10$ \\
\hline COM & 13,7 & 32,1 & 193,8 & 167,1 & 438,5 & 4,8 & 3,6 & 18,8 & 1,2 & 141,7 & 179,9 & 90,2 & 26,0 \\
\hline SEM & 9,9 & 24,7 & 161,6 & 135,7 & 360,2 & 1,9 & 1,2 & 16,0 & 0,0 & 111,0 & 155,4 & 60,4 & 13,6 \\
\hline Texas (EMA) & 13,5 & 30,9 & 170,2 & 72,3 & 365,0 & 2,8 & 3,8 & 16,8 & 2,1 & 126,5 & 152,2 & 75,8 & 23,3 \\
\hline Squitter & & & & & & & 3,5 & 13,8 & 1,8 & 125,0 & 157,0 & 75,8 & 23,3 \\
\hline desvio padrao $(\mathrm{mm})$ & 1,8 & 3,3 & 13,6 & 39,4 & 35,8 & 1,2 & 1,0 & 1,8 & 0,8 & 10,9 & 11,0 & 10,5 & 4,7 \\
\hline AMP Com x Sem $(\mathrm{mm})$ & 3,8 & 7,4 & 32,2 & 31,5 & 78,3 & 3,0 & 2,4 & 2,7 & 1,2 & 30,7 & 24,4 & 29,8 & 12,5 \\
\hline AMP Com x Ema (mm) & 0,2 & 1,2 & 23,6 & & 73,5 & 2,0 & $-0,2$ & 2,0 & $-0,9$ & 15,2 & 27,7 & 14,4 & 2,7 \\
\hline AMP Com x SQT (mm) & & & & & & & 0,1 & 5,0 & $-0,5$ & 16,7 & 22,9 & 14,5 & 2,8 \\
\hline indice de variação & & & & & & & 1,04 & 1,37 & 0,69 & 1,13 & 1,15 & 1,19 & 1,12 \\
\hline
\end{tabular}

No geral, os dados que compõem a Tabela 2 apresentaram em torno de 83,01 mm de média com desvio padrão (S) de $\pm 103,31$ e coeficiente de variação (CV) de 1,24. Foi notável a existência de erro grosseiro na coleta dos dados referentes a 13 a 31/janeiro (amostra 4, 72,3mm - grafado em vermelho) - irreparável, e devido a isso, excluido da análise posterior. Nota-se também que o maior desvio $(39,4$ $\mathrm{mm}$ ) referiu-se a esta amostra, porém, entre fevereiro e o começo de março obtivemos as maiores alturas de chuva na amostra 5 (acima dos $350 \mathrm{~mm}$ ) de $\mathrm{S}=35,8$ também elevado - característicos do verão; os menores desvios (abaixo de 13,6 mm) foram registrados em totais pluviométricos inferiores a $200 \mathrm{~mm}$; na amostra 9 referente a abril obtivemos as menores totalizações e o menor $\mathrm{S}(0,8)$.

As maiores amplitudes ou diferenças foram observadas em valores médios próximos a $20 \mathrm{~mm}(\mathrm{~S}=21,7$ e $\mathrm{CV}=1,08)$ quando considerada a relação dos equipamentos Com x Sem principalmente no verão mas também no final do inverno e início da primavera. As diferenças encontradas entre Com x Ema são da casa dos 13,5 mm ( $\mathrm{S}=21,3$ e $\mathrm{CV}=1,58)$. As menores amplitudes foram registradas na comparação entre os equipamentos Com x Squitter ( 7 amostras): com $8,8 \mathrm{~mm}$ de amplitude média e $\mathrm{S}=9,2$, entretanto, com menor $\mathrm{CV}=1,05$ e referem-se ao final do inverno e meados da primavera. $\mathrm{Na}$ média, as amplitudes foram menores entre o pluviômetro Com funil e o automático Squitter. O índice de variação entre esses dois equipamento conduz a totais obtidos no conjunto 'Com funil' superiores em torno de $1 \mathrm{vez}$ àqueles obtidos no Squitter. 
Na Tabela 3 são apresentados os resultados dos coeficientes de determinação tendo como base o pluviômetro Com funil. Os valores de $\mathrm{R}^{2}$ indicam, distando menos de $5 \%$ da melhor possibilidade de explicação da relação de seus totais com as áreas de captação, que os equipamentos individualmente apresentam alta relação com aquele referencial. A melhor relação encontrada foi entre o equipamento Com e o Squitter $(0,99920)$.

Tabela 3 - Coeficientes de determinação entre os pluviômetros utilizados no estudo.

\begin{tabular}{|c|c|c|c|}
\hline $\mathbf{R}^{\mathbf{2}}$ & Sem & Ema & Squitter \\
\hline Com & 0,99730 & 0,96520 & 0,99920 \\
\hline
\end{tabular}

As figuras $4(\mathrm{a}, \mathrm{b}$ e c), representam os gráficos referentes às retas de regressão obtidas e seus respectivos coeficientes de determinação e correlação. Os valores de $\mathrm{R}$ são menores na correlação Com x Ema $(0,9825)$ e maiores na correlação Com x Squitter $(0,9996)$, apresentando, ainda assim, alta correlação positiva diretamente proporcional entre eles.

$\mathrm{Na}$ aplicação da distribuição t-Student, encontramos valores calculados superiores a tabela referente que confirmam a existência de uma correlação significativa entre Com x Sem, Com x Ema e Com x Squitter, respectivamente; considerando-se que para um nível de probabilidade de 0,05 (95\%) e um número de coletas de 13 (Com x Sem e Com x Ema) e 7 na relação (Com x Squitter) tem-se o valor de $1,771,1,771$ e 1,895 .
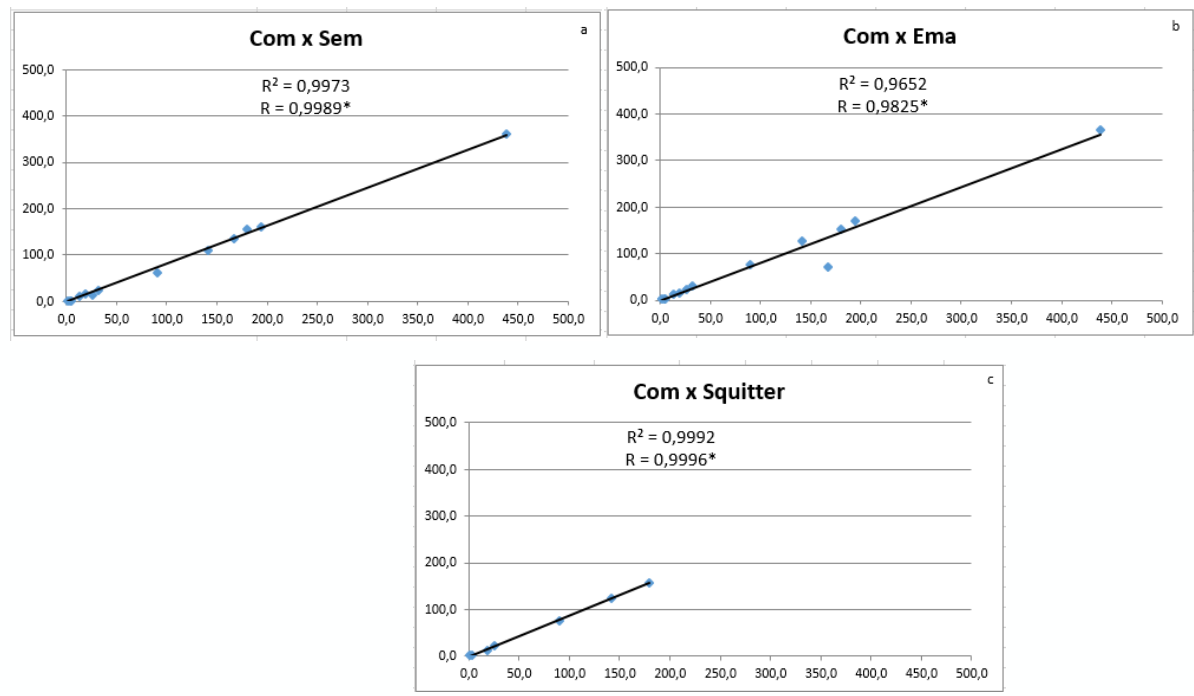

Figura 4. Correlação entre os totais pluviométricos obtidos em diferentes equipamentos: Com funil x Sem funil (a), Com funil x Ema (b) e Com funil x Squitter (c). Os valores obtidos do coeficiente de correlação (R) seguidos de asterisco (*) indicam que é significativo ao nível de $95 \%$ de probabilidade (alfa=0,05).

\section{Conclusões}

A análise comparativa dos resultados apontou para as seguintes conclusões: 
- O controle natural exercido pelo sítio da instalação foi minimizado transaparecendo a importância do coeficiente de determinação $\left(\mathrm{R}^{2}\right)$ que realçou a pluviometria conforme a dimensão da superfície coletora: quanto maior, mais aproximada da realidade;

- Houve relativa homogeneidade entre as amplitudes principalmente no verão, relacionadas à gênese convectiva no período e maiores variações no outono inverno - ocorrendo diferenciação significativa dos valores de chuva quando relacionados os totais aos sistema atmosférico atuante (totais mais baixos remeteram à maior heterogeneidade);

- Os valores dos equipamentos automáticos tenderam a apresentar alturas de chuva inferiores àquelas coletadas pelos experimentais - subvalores são encontrados devido a vários controles e aqui possivelmente estão ligados à intensidade das precipitações convectivas, que no mundo tropical conduzem à ultrapassagem comum dos limites de erro propostos por cada equipamento automático conforme observado em Braga e Fernandes (2007) e Braga et al. (2007);

- Considerando-se o elevado coeficiente de correlação entre o pluviômetro experimental COM funil e o pluviômetro Squitter ( $\mathrm{R}=0,9996)$ e o reduzido Índice de variação de 1,1 (média), propõe-se um valor correcional de 9,2 mm, baseado no desvio padrão das amplitudes absolutas para os valores do equipamento automático quando utilizados concomitantemente, no intuito de minimizar tais diferenças.

\section{Referências}

CHEVALLIER, P. Aquisição e processamento de dados. In: TUCCI, C.E.M. Hidrologia: Ciência e aplicação. Porto Alegre, Ed. UFRGS/EDUSP/ ABRH, 1993. p.485-525.

BRAGA, S;M.; FERNANDES, C.V.S. Performance de Sensores de Precipitação do Tipo "TippingBucket" (Báscula) - Um Alerta para a Ocorrência de Erros. Revista Brasileira de Recursos Hídricos, 2007. v. 12, n. 1, pp. 197-204.

BARATTO, J.; WOLLMANN, C. A.; HOPPE, I. L. Distribuição da precipitação pluviométrica no período veranil e invernal de 2013/2014 na área urbana de Santa Maria/RS e seu entorno. Ciência e Natura, v. 37, p. 577-593, 2015.

BRAGA, S.M.; DELARIZZA, R.A.; SANTOS, I.; FERNANDES, C.V.S. Avaliação da performance de pluviômetros de báscula: técnicas para a realização de ensaios pluviométricos em laboratório. In: XVII Simpósio Brasileiro de Recursos Hídricos e $8^{\circ}$ Simpósio de Hidráulica e Recursos Hídricos dos Países de Língua Oficial Portuguesa, 2007, São Paulo. XVII Simpósio Brasileiro de Recursos Hídricos. Porto Alegre: ABRH, 2007. v. 1. p. 1-16.

BRAGA, S.M.; FERNANDES, C.V.S.; BRAGA, A.S.; SANTOS, I. Avaliação da performance de pluviômetros de báscula: Sub-medição durante eventos extremos e novos esquemas de medição. In: II SIMPÓSIO DE RECURSOS HÍDRICOS DO SUL-SUDESTE, 2008, Rio de Janeiro. ANAIS DO II SIMPÓSIO DE RECURSOS HIIDRICOS DO SUL-SUDESTE. Porto Alegre: ABRH, 2008.

BRAGA, S.M.; FERNANDES, C.V.S; Performance de Sensores de Precipitação do Tipo "TippingBucket" (Báscula) - Um Alerta para a Ocorrência de Erros. Revista Brasileira de Recursos Hídricos, 2007.

LIMA, N. G. B. Análise microclimática dos manguezais da Barra do Ribeira-Iguape/SP. 2009.185f. Dissertação de mestrado (Programa de Pós-graduação em Geografia Física). Faculdade de Filosofia, Letras e Ciências Humanas da Universidade de São Paulo, 2009. 
SENTELHAS, P. C. etal.Análise comparativa de dados meteoro lógicos obtidos por estações convencional e automática. Rev. Bras. Agrometeorol., Santa Maria, v.5, n.2, p.215-221,1997.

SOUZA, I. A.; GALVANI, E.; ASSUNÇÃO. H. F. Estudo comparativo entre elementos meteorológicos monitorados por estações convencional e automática na região de Maringá, Estado do Paraná. Acta Scientiarum Technology Maringá, v. 25, no. 2, p. 203-207, 2003.

SOUZA, J. L. M.; SCHÄFER, R. F.; SCHÄFER, H.; JERSZURKI, D. Precipitação medida com pluviômetrosalternativos na região de Curitiba, Estado do Paraná. Revista Acadêmica: Ciências Agrárias e Ambientais, v. 11, Supl. 2, p. 83-93, 2013.

SOUZA, L F. et al. Comparação de dados meteorológicos obtidos em estações convencional e automática do Distrito de Irrigação do Platô de Neópolis. In: CONGRESSO BRASILEIRO DE METEOROLOGIA, 2000,11, Rio de Janeiro. CD-ROM ... Rio de Janeiro: Sociedade Brasileira de Meteorologia, 2000.

WMO (World MeteorologicalOrganization). Guia de Instrumentos y Métodos de Observación Meteorológicos. Geneva. Sexta edição, nº 8, 1996. 